\title{
The Effects of Aroma Foot Baths on Stress and Sleep in Terminal Cancer Patients
}

\author{
Bok Soon Kim, R.N., Sun Hwa Chae, R.N. and In Cheol Hwang, M.D.* \\ Departments of Nursing and "Family Medicine, Gil Medical Center, Gachon University College of Medicine, Incheon, Korea
}

Purpose: This study aimed to investigate the effects of aroma foot baths on stress and sleep in terminally ill cancer patients. Methods: We performed a non-randomized interventioncontrol study with 30 terminal cancer patients who were admitted to a palliative care unit. Participants responded to questionnaires on stress and sleep before and after a 5-day interval. The intervention group received a daily aroma foot bath for 5 days. We performed multivariate regression analysis to examine the changes in outcomes on stress and sleep for the intervention group compared to the control group. Results: The differences in baseline characteristics between groups, excluding subjective economic status and general weakness, did not show statistical significance. In contrast to the control group, the intervention group showed a statistically significant change in physical stress and psychological stress levels, but significant changes were not observed in quality of sleep. Compared to the control group, the intervention group showed a significant reduction in physical stress $(\mathrm{P}=0.068)$ and psychological stress $(\mathrm{P}=0.021)$. Conclusion: Aroma foot baths are effective for reducing stress in patients hospitalized with terminal cancer.

Key Words: Aromatherapy, Foot baths, Psychological stress, Sleep, Neoplasms, Terminal care
Received January 7, 2021

Revised March 18, 2021

Accepted March 19, 2021

\section{INTRODUCTION}

Terminal cancer patients are defined as those who receive curative care such as surgery or chemotherapy after being diagnosed with cancer but are unlikely to expect any further recovery. They often face various psychological and social issues in addition to physical pain due to their uncertain future, the feeling of having an unresolved past, spiritual considerations, relationships, and the stress of prolonged cancer treatment [1]. The constant stress experienced by these patients causes further psychological instability that often blurs their judgment and leads to poor decision-making [2]. Among the many problems experienced by terminal cancer patients, sleep disorders simultaneously act as a cause and an effect of such psycho-social issues. Lack of adequate sleep may aggravate one's symptoms and cause patients to think of the disease in a more severe way [3].

A complementary and alternative medicine approach is needed for patients who do not react well to conventional evidence-based treatment. Such an approach can be more useful for terminal cancer patients with conditions that are difficult to control and often lead to psycho-social issues [4]. Aromatherapy is one of the most popular therapies in complementary and alternative medicine, providing numerous psychological and physical effects through the use of aromatic oils extracted from plants to directly stimulate the limbic system, which controls instinct, emotions, and memory, through one's skin and sense of smell [5]. Internationally, aromatherapy is particularly 
widely used for cancer patients to relieve physical and mental stress, improve stress-related symptoms, and help with pain and sleep $[6,7]$. Foot baths are another popular alternative therapy and are known to be effective for maintaining homeostasis and reducing fatigue and stress by stimulating the feet with warm water, heating up the whole body, helping blood circulation, and promoting one's metabolism. A foot bath can be performed easily and simply without exerting pressure on the body, as opposed to a full bath or a lower-body bath, and can achieve a satisfying effect using only a small amount of water. However, there are conflicting views on the effect of foot baths on sleep [8,9].

There has been no previous research on the effects of foot baths on managing the symptoms of cancer patients in South Korea. There have been a few studies that investigated the effects of aromatherapy for alleviating physical symptoms [1012] and psychological issues $[10,12,13]$ and one study that $\mathrm{ex}^{-}$ amined the effects of foot reflex massages using aroma oils on cancer patients living in a care facility [14]. Few studies have examined a combination of both therapies at the same time, even globally, except for a small number of pregnant women $[15,16]$. This study investigated the effects of aroma foot baths on terminal cancer patients hospitalized in palliative care units. The hypotheses of the study were: 1) the intervention group, which received aroma foot baths, would experience stress relief compared to the control group, and 2) the intervention group, which received aroma foot baths, would experience improved sleep patterns and sleep quality compared to the control group.

\section{METHODS}

\section{Study design}

This study followed a nonequivalent control-group pretestposttest design, which included an initial survey for both the aroma foot bath group and the control group followed by a second survey after 5 days to measure participants' levels of stress and sleep satisfaction. The dates were different for the intervention group and the control group to prevent diffusion of the effect of the experiment, and before-and-after effects were measured first in the control group, followed by the intervention group.

\section{Participants}

The study was conducted on terminal cancer patients hospitalized in the palliative care unit of a university hospital in Incheon between November 2017 and September 2020. The patients were aged between 20 and 80, had the cognitive ability to communicate and answer surveys, and agreed to participate after receiving sufficient information on the study. Patients who were discharged, showed a decline in cognitive ability due to aggravated conditions, showed weakness or fatigue, or experienced discomfort caused by aromatherapy during the study withdrew consent and stopped treatment. No specific formula was used to calculate the required number of participants due to the lack of previous studies to provide a foundation. The researcher set the number of participants for each group at 15 patients, considering the circumstances of the unit.

\section{Intervention}

Both groups were provided with the usual services commonly offered by hospice palliative care institutions as designated by the Ministry of Health and Welfare of South Korea, including various therapies, physical symptom control, mental support, and spiritual care provided by volunteers. The control group was not provided with any intervention, while the intervention group was provided with an aroma foot bath once a day for 5 days. Aroma foot baths were provided for those in the control group who wanted them after the experiment was over.

Lavender oil and sweet orange oil were selected since they are known to be effective at relieving stress and improving sleep, according to the literature and an international aromatherapy expert. Lavender is the most significant component in aromatherapy, reducing stress by relaxing the body and the mind, and sweet orange is often used for treating sleep issues, hypersensitivity, and anxiety, and has a sweet and refreshing aroma [17]. The essential oils were diluted to a $1.5 \%$ concentration according to a previous study [12], and a 2:1 ratio of lavender to sweet orange was added to the foot bath water. The foot bath was performed by immersing the participant's feet in the water up to $5 \mathrm{~cm}$ above the ankles. The water temperature was chosen based on a previous study suggesting that sleep patterns improved after performing foot baths for 3 days or more with a foot bath machine maintaining a temperature between $40^{\circ} \mathrm{C}$ 
and $43^{\circ} \mathrm{C}$ [18]. Considering that terminal cancer patients may find it difficult to sit in the same position for a long time [12], foot baths were given at a time of day that was convenient to the patient for 20 minutes a day for 5 consecutive days.

\section{Study tools}

To measure stress, we used a tool developed by Park [19] in 1999. This tool consisted of 30 questions in two areas: 15 on physical stress and 15 on psychological stress. Answers are measured on a Likert scale from 0 to 3, with 0 indicating "not at all" and 3 indicating "always". Thus, a higher score indicated a higher level of stress. The Cronbach's alpha values at the time of the tool's development were 0.887 for physical stress and 0.881 for psychological stress. They were 0.833 and 0.906 in this study.

Sleep patterns and subjective quality of sleep were measured to understand the effects of the treatment on sleep. To measure sleep patterns, we used Kim's [20] 11-item tool-a revised and modified version of a 1987 tool created by Sydner-Halpen and Verran. This tool used a Likert scale from 1 to 4 , with 1 indicating "extremely" and 4 indicating "not at all". Total possible scores ranged from 11 and 44, with a higher score indicating better sleep. The Cronbach's alpha values were 0.76 at the time of the tool's development, 0.86 in the Kim study, and 0.911 in this study. Subjective quality of sleep was measured with a tool developed in 2004 by Song and Kim [21] - a modified version of the 1988 Wong-Baker FACES Pain Rating Scale. The tool was based on a 6 -point Likert scale $(0 \sim 5)$, with higher scores indicating better sleep quality.

The following information on participants was collected from the medical records of those receiving inpatient hospice services: age, sex, marriage status, religion, education, and family caregiver information. Additional data collected for the purposes of this study were average sleep hours, subjective financial status, and energy levels. Subjective financial status was determined using a survey with six possible choices ranging from "very sufficient" to "very insufficient". Responses were classified into two groups-those who answered that their finances were "insufficient" or "very insufficient", and those who answered otherwise. Energy level was determined using a survey with four possible choices, ranging from "not at all", "normal", "slightly high", to "high", and the results were analyzed by classifying the responses into two groups-those who answered "not at all" and everyone else.

\section{Ethical considerations}

The protocol of this study was pre-approved by the Institutional Review Board of the same institution (Approval number: GAIRB 2017-284).

\section{Data analysis}

Differences in the characteristics of participants between the intervention and control groups were compared using the $\mathrm{t}^{-}$ test and chi-square test. Changes in stress levels and quality of sleep in each group after intervention were confirmed using

Table 1. Characteristics of Participants ( $N=30)$.

\begin{tabular}{|c|c|c|c|}
\hline \multirow{2}{*}{ Variables } & \multirow{2}{*}{$\begin{array}{c}\text { Control } \\
\text { group }(n=15) \\
\text { Mean } \pm \text { SD or } \\
n(\%)\end{array}$} & \multirow{2}{*}{$\begin{array}{c}\text { Experimental } \\
\text { group }(n=15) \\
\text { Mean } \pm \text { SD or } \\
n(\%)\end{array}$} & \multirow{2}{*}{ P-value } \\
\hline & & & \\
\hline Age (yr) & $58.4 \pm 8.8$ & $58.5 \pm 14.6$ & 0.976 \\
\hline \multicolumn{4}{|l|}{ Sex } \\
\hline Male & $6(40)$ & $5(33.3)$ & \multirow[t]{2}{*}{0.705} \\
\hline Female & $9(60)$ & $10(66.7)$ & \\
\hline \multicolumn{4}{|l|}{ Marital status } \\
\hline Married & $10(66.7)$ & $10(66.7)$ & \multirow[t]{2}{*}{1.000} \\
\hline Others* & $5(33.3)$ & $5(33.3)$ & \\
\hline \multicolumn{4}{|l|}{ Religion } \\
\hline Protestant & $8(53.3)$ & $5(33.3)$ & \multirow[t]{4}{*}{0.409} \\
\hline Catholic & $2(13.3)$ & $2(13.3)$ & \\
\hline Buddhist & $3(20.0)$ & $2(13.3)$ & \\
\hline None & $2(13.3)$ & $6(40.0)$ & \\
\hline \multicolumn{4}{|l|}{ Education level } \\
\hline Middle school or less & $8(53.3)$ & 5 (33.3) & \multirow[t]{2}{*}{0.269} \\
\hline High school or more & $7(46.7)$ & $10(66.7)$ & \\
\hline \multicolumn{4}{|l|}{ Main caregiver } \\
\hline Spouse & $8(53.3)$ & $7(46.7)$ & \multirow[t]{2}{*}{0.717} \\
\hline Others $^{\dagger}$ & $7(46.7)$ & $8(53.3)$ & \\
\hline \multicolumn{4}{|c|}{ Subjective economic status } \\
\hline Average or more & $9(60.0)$ & $13(86.7)$ & \multirow[t]{2}{*}{0.099} \\
\hline Insufficient & $6(40.0)$ & $2(13.3)$ & \\
\hline $\begin{array}{l}\text { Mean sleep duration } \\
\text { (hours) }\end{array}$ & $5.5 \pm 2.9$ & $6.9 \pm 2.5$ & 0.193 \\
\hline \multicolumn{4}{|l|}{ Energy level } \\
\hline Low & $11(73.3)$ & 5 (33.3) & \multirow[t]{2}{*}{0.028} \\
\hline Average or more & $4(26.7)$ & $10(66.7)$ & \\
\hline
\end{tabular}

*Including single, divorced, or separated with or without death.

${ }^{\dagger}$ Including offspring, parents, and siblings.

${ }^{\dagger}$ From the independent t test or chi-square test. 
the paired $\mathrm{t}$-test, and the changes in the intervention group were finally verified using multivariate regression analysis. All analyses were performed using the statistical analysis software STATA SE 9 (STATA Corporation, Texas, US), and P $>0.1$ was considered to indicate statistical significance in the two-tailed test.

\section{RESULTS}

\section{Verification of homogeneity between the control and intervention groups pre-intervention}

The baseline characteristics of the participants can be found in Table 1. Few significant differences between the two groups were found for almost all variables. The proportion of participants in the control group who answered that their subjective financial state was "insufficient" (40.0\% in the control group vs. $13.3 \%$ in the intervention group; $\mathrm{P}=0.099)$ and who reported a low energy level $(73.3 \%$ in the control group vs. $33.3 \%$ in the intervention group; $\mathrm{P}=0.028$ ) was significantly higher than in the intervention group.

\section{Verification of the effects of intervention}

Changes in stress levels and quality of sleep based on measurements taken before and after the intervention for each group can be found in Table 2. For the control group, no significant changes were found across all items. However, for the intervention group, significant changes were observed in terms

Table 2. Changes in Levels of Stress and Quality of Sleep.

\begin{tabular}{lrrrr}
\hline \multirow{2}{*}{ Variables } & Pre-test & & Post-test & \\
\cline { 2 - 2 } \cline { 5 - 5 } & Mean \pm SD & & Mean \pm SD & \\
\hline Control & & & \\
Physical stress & $13.5 \pm 7.4$ & & $15.3 \pm 6.7$ & 0.193 \\
Psychological stress & $12.4 \pm 8.9$ & & $13.6 \pm 9.2$ & 0.423 \\
Overall sleep & $33.5 \pm 8.5$ & & $31.0 \pm 6.1$ & 0.134 \\
Quality of sleep & $2.7 \pm 1.2$ & & $2.5 \pm 0.8$ & 0.582 \\
Intervention & & & \\
Physical stress & $17.7 \pm 6.3$ & & $13.6 \pm 6.7$ & 0.069 \\
Psychological stress & $14.9 \pm 7.2$ & & $10.5 \pm 7.0$ & 0.031 \\
Overall sleep & $31.2 \pm 5.5$ & & $31.4 \pm 7.3$ & 0.891 \\
Quality of sleep & $1.9 \pm 1.0$ & $2.9 \pm 1.1$ & 0.068 \\
\hline
\end{tabular}

*From the paired t-test. of physical stress (17.7 \pm 6.3 vs. $13.6 \pm 6.7 ; \mathrm{P}=0.069)$, psychological stress $(14.9 \pm 7.2$ vs. $10.5 \pm 7.0 ; \mathrm{P}=0.031)$, and quality of sleep ( $1.9 \pm 1.0$ vs. $2.9 \pm 1.1 ; \mathrm{P}=0.068)$.

Table 3 shows the effects of the aroma foot baths. The results indicate significant changes in stress levels and quality of sleep for the intervention group compared to the control group after adjustment for subjective financial state and energy level, which showed significant differences between groups in Table 1. Aroma foot baths had significant effects on physical stress $(1.70 \pm 1.96$ vs. $-3.96 \pm 1.96 ; \mathrm{P}=0.068)$ and psychological stress ( $1.60 \pm 1.72$ vs. $-4.80 \pm 1.72 ; P=0.021$ ), but did not have a significant effect on sleep quality.

Figure 1 shows how the effects of aroma foot baths varied according to the reported subjective energy level within the intervention group. The level of stress decreased and quality of sleep improved for the group that reported having average or more energy as opposed to the group that reported a lower subjective energy level. However, not all outcomes were statis-

Table 3. Changes in Levels of Stress and Quality of Sleep after Aroma Foot Baths.

\begin{tabular}{lccccc}
\hline \multirow{2}{*}{ Variables } & Control group & & \multicolumn{2}{c}{ Interventiongroup } & \\
\cline { 2 - 2 } \cline { 5 - 5 } & Mean \pm SE & & \multicolumn{2}{c}{ Mean \pm SE } & \\
\hline Physical stress & $1.70 \pm 1.96$ & & $-3.96 \pm 1.96$ & 0.068 \\
Psychological & $1.60 \pm 1.72$ & & $-4.80 \pm 1.72$ & 0.021 \\
stress & & & & \\
Overall sleep & $-2.89 \pm 1.66$ & & $0.56 \pm 1.66$ & 0.183 \\
Quality of sleep & $-0.13 \pm 0.47$ & & $0.87 \pm 0.47$ & 0.169 \\
\hline
\end{tabular}

*From the regression models with adjustment for subjective economic status and energy level.

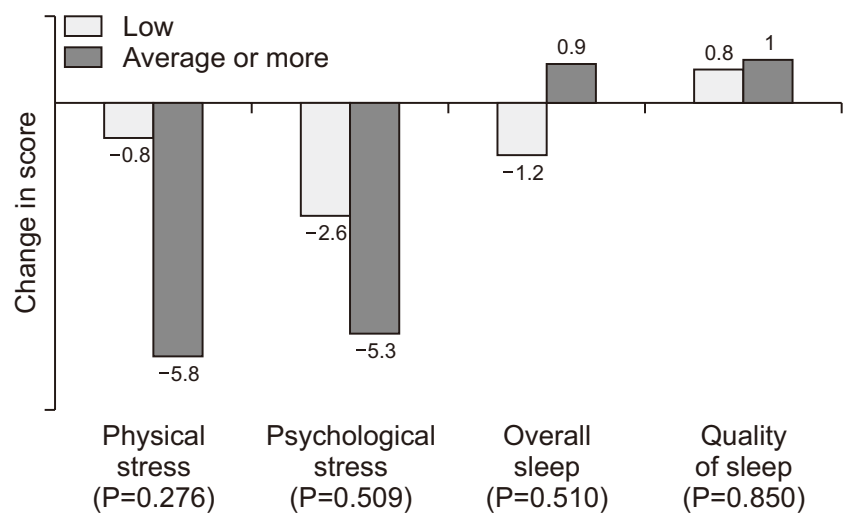

Figure 1. Changes in stress levels and quality of sleep according to subjective energy level in the intervention group. 
tically significant.

\section{DISCUSSION}

Cancer patients, especially those closer to the end stages of a terminal diagnosis, can be easily influenced to try treatments that are not scientifically proven [4]. The authors believe that verifying the effects of word-of-mouth therapies or creating new foundations by combining treatments that already have verified effects is one of the responsibilities of healthcare providers who specialize in hospice and palliative care. In this study, we examined the effects of aroma foot baths on stress levels and quality of sleep among terminal cancer patients. Aroma foot baths have been proven to have significant positive effects in terms of both physical and psychological stress, while no statistically significant change was found for quality of sleep. The results of the detailed analysis indicate that the effects of aroma foot baths can potentially vary according to a patient's subjective energy level, although the significance of this effect was not verified.

The type of aroma foot bath performed in this study combines the benefits of aromatherapy and foot baths, which have had proven effects in a number of clinical situations. EffatiDaryani et al. [15] found that lavender cream with foot baths significantly reduced stress, anxiety, and depression levels in a study of 141 pregnant women. The results of a study on the effects of aromatherapy on anxiety in the first stage of labor showed a significant decrease in anxiety in the intervention group compared to the control group and the foot bath-only group [16]. In this study, aroma foot baths had significant effects on reducing the stress of terminal cancer patients, which was predictable based on the results of existing studies on the effects of foot baths [22,23] and aromatherapy [24] in terms of stress.

Foot baths are effective at reducing pain by promoting blood circulation and relaxing the body, ultimately inducing sleep $[25,26]$. In addition to their effectiveness, foot baths are widely used in ordinary life because they are affordable and have few side effects. Similarly, aromatherapy has been proven to have a positive effect on healthy sleep by a relatively high number of studies [27]. Many studies have shown the significant effects of foot baths or aromatherapy on improved sleep. A study from
Taiwan [28] on elderly people with sleep disorders aged 60 to 75 was most comparable to this study compared to two Japanese studies [8,29] on the effects of foot baths and aroma foot baths on young and healthy women in their teens and twenties. The Taiwanese study showed that 40-minute foot baths for 2 consecutive days had positive effects on some indicators of polysomnography. However, this result is not immediately comparable to the results of this study. First, the participants in that study were not as vulnerable as the terminal cancer $\mathrm{pa}^{-}$ tients who participated in this study. Participants with chronic conditions such as hypertension or arrhythmia were included in their study, but the sample was limited to those with controlled symptoms. Terminal cancer patients often experience symptom clusters [30], meaning that it may be more difficult to understand the effects of certain therapies on sleep due to persistent negative interactions between symptoms. Second, this study had a relatively short period of time to evaluate the effects of treatment compared to other studies, since participants in this study were patients with an average of only 1 month to live.

The limitations of this study are as follows. First, the number of participants was not sufficient for making a definitive conclusion, and caution should be used when generalizing the results since the study was performed at a single institution. Further research should be conducted across multiple institutions, including advisory hospices so that participants at earlier stages can also be selected for research. This will allow for a longer intervention period and inclusion of patients with higher energy levels, which may help lead to more reliable conclusions. With enough participants, it would be ideal to evaluate the effects of aroma foot baths using more detailed research by studying additional groups that received either aromatherapy or foot baths only. Second, the outcomes may simply be the results of psychological effects given that a blinded experiment is essentially impossible. However, we believe the results can be verified with more objective post-treatment indicators such as blood cortisol levels or polysomnography. Obtaining approval for performing these tests on terminal cancer patients with an average of just 1 month to live was difficult not only from the institutional review board, but also from patients and caregivers. Last but not least, the study did not conduct a detailed evaluation of treatments for controlling other symptoms 
such as pain, anxiety, and depression that may have directly or indirectly affected stress or sleep.

Despite the limitations, this study is meaningful since it is the first study to examine the effects of aroma foot baths on the stress levels and quality of sleep of terminal cancer patients. It is hoped that the outcomes of this study are helpful for medical staff who care for patients in clinical settings as well as for future researchers.

\section{ACKNOWLEDGMENTS}

The authors thank the participants who bravely shared their experiences. This research received no specific grant from any funding agency in the public, commercial, or not-for-profit sectors.

\section{CONFLICT OF INTEREST}

No potential conflict of interest relevant to this article was reported.

\section{ORCID}

Bok Soon Kim, https://orcid.org/0000-0003-0710-7591

Sun Hwa Chae, https://orcid.org/0000-0002-5452-4278

In Cheol Hwang, https://orcid.org/0000-0003-4677-5525

\section{AUTHOR'S CONTRIBUTIONS}

Conception or design of the work: BSK, ICH. Data collection: BSK, SHC. Data analysis and interpretation: BSK, SHC, ICH. Drafting the article: BSK. Critical revision of the article: BSK, SHC, ICH. Final approval of the version to be published: BSK, SHC, ICH.

\section{SUPPLEMENTARY MATERIALS}

Supplementary materials can be found via https://doi. org/10.14475/jhpc.2021.24.2.109.

\section{REFERENCES}

1. Lee WH. Total pain of patient with terminal cancer. Korean J Hosp Palliat Care 2000;3:60-73.

2. Isikhan V. Coping with stress in patients with advanced cancer. Asian Pac J Cancer Prev 2010;11 Suppl 1:81-92.

3. Kawada T. Sleep disturbance and emotional distress in patients with advanced cancer. J Pain Symptom Manage 2016;52:e3-4.

4. Jones E, Nissen L, McCarthy A, Steadman K, Windsor C. Exploring the use of complementary and alternative medicine in cancer patients. Integr Cancer Ther 2019;18:1534735419854134.

5. Farrar AJ, Farrar FC. Clinical aromatherapy. Nurs Clin North Am 2020;55:489-504.

6. Reis D, Jones T. Aromatherapy: Using essential oils as a supportive therapy. Clin J Oncol Nurs 2017:21:16-9.

7. Louis M, Kowalski SD. Use of aromatherapy with hospice patients to decrease pain, anxiety, and depression and to promote an increased sense of well-being. Am J Hosp Palliat Care 2002;19:381-6.

8. Sung EJ, Tochihara Y. Effects of bathing and hot footbath on sleep in winter. J Physiol Anthropol Appl Human Sci 2000;19:21-7.

9. Liao WC, Wang L, Kuo CP, Lo C, Chiu MJ, Ting H. Effect of a warm footbath before bedtime on body temperature and sleep in older adults with good and poor sleep: an experimental crossover trial. Int J Nurs Stud 2013;50:1607-16.

10. Sohn KJ, Kim MJ, Lee JB, Kim SH, Kim JA, Jung HH, et al. The effects of aroma self massage in hands on pain, depressive mood and anxiety in breast cancer patients. Korean J Hosp Palliat Care 2005;8:18-29.

11. Kim SA, Kim SJ, Chung J, Lee SY, Han MS, Oh SH, et al. The effect of aroma therapy on lower extremity edema of terminal cancer patients: a controlled trial. Korean J Hosp Palliat Care 2009;12:139-46.

12. Chang SY. Effects of aroma hand massage on pain, state anxiety and depression in hospice patients with terminal cancer. J Korean Acad Nurs 2008;38:493-502.

13. Yun SH, Cha JH, Yoo YS, Kim YI, Chung SM, Jeong HL. Effects of aromatherapy on depression, anxiety and the autonomic nervous system in breast cancer patients undergoing adjuvant radiotherapy. Korean J Hosp Palliat Care 2012;15:68-76.

14. Lee SJ, Kim IL, Kang KK, Moon KR. The influence of foot reflexology massage using aroma oil on sleep an pain in cancer patients. J Kor Inst Electron Commun Sci 2013;8:1609-16.

15. Effati-Daryani F, Mohammad-Alizadeh-Charandabi S, Mirghafourvand M, Taghizadeh M, Mohammadi A. Effect of Lavender Cream with or without Foot-bath on Anxiety, Stress and Depression in Pregnancy: a Randomized Placebo-Controlled Trial. J Caring Sci 2015;4:63-73. 
16. Kheirkhah M, Vali Pour NS, Nisani L, Haghani H. Comparing the effects of aromatherapy with rose oils and warm foot bath on anxiety in the first stage of labor in nulliparous women. Iran Red Crescent Med J 2014;16:e14455.

17. Choi YS, Shon GJ, Kim MJ. Aromatherapy in hospice. Korean J Hosp Palliat Care 2004;7:1-7.

18. Seo HS, Sohng KY. The effect of footbaths on sleep and fatigue in older Korean adults. J Korean Acad Fundam Nurs 2011;18:488-96.

19. Park SY. Stress measurement tool. Gwangju Metropolitan City Seo-gu Public Health News 1999;11:2.

20. Kim HY. A survey of sleep state, sleep promoting activities, sleep disturbing factors and their relationship in abdominal \& thoracic surgery patients [master's thesis]: Seoul: Seoul National Univ.; 2001.

21. Song RH, Kim DH. The effect of foot reflexion massage on the sleep, depression and physiological index in the facility-cared elderly. Journal of the Korea Gerontological Society 2006;26:31-43.

22. Yamamoto K, Nagata S. Physiological and psychological evaluation of the wrapped warm footbath as a complementary nursing therapy to induce relaxation in hospitalized patients with incurable cancer: a pilot study. Cancer Nurs 2011;34:185-92.

23. Lee JH, Seo EK, Shim JS, Chung SP. The effects of aroma massage and foot bath on psychophysiological response in stroke patients. J Phys Ther Sci 2017;29:1292-6.

24. Atsumi T, Tonosaki K. Smelling lavender and rosemary increases free radical scavenging activity and decreases cortisol level in saliva. Psychiatry Res 2007:150:89-96.

25. Liao WC, Landis CA, Lentz MJ, Chiu MJ. Effect of foot bathing on distal-proximal skin temperature gradient in elders. Int J Nurs Stud 2005;42:717-22.

26. Saeki Y, Nagai N, Hishinuma M. Effects of footbathing on autonomic nerve and immune function. Complement Ther Clin Pract 2007;13:15865.

27. Hwang E, Shin S. The effects of aromatherapy on sleep improvement: a systematic literature review and meta-analysis. J Altern Complement Med 2015;21:61-8.

28. Liao WC, Chiu MJ, Landis CA. A warm footbath before bedtime and sleep in older Taiwanese with sleep disturbance. Res Nurs Health 2008;31:514-28.

29. Saeki Y. The effect of foot-bath with or without the essential oil of lavender on the autonomic nervous system: a randomized trial. Complement Ther Med 2000;8:2-7.

30. Stapleton SJ, Holden J, Epstein J, Wilkie DJ. Symptom clusters in patients with cancer in the hospice/palliative care setting. Support Care Cancer 2016;24:3863-71. 